\title{
GROWTH, STRUCTURAL AND OPTICAL STUDIES OF PURE AND KBR DOPED ADP CRYSTALS
}

\author{
N.Siva ${ }^{1}$, S.Perumal ${ }^{2}$, K.Monikanda Prabu $^{3}$ \\ ${ }^{1}$ Principal, KNSK Polytechnic College, Nagercoil, Tamilnadu, India. \\ ${ }^{2}$ Principal, S.T.Hindu College, Nagercoil, Tamilnadu, India. \\ ${ }^{3}$ Research Scholar, Physics Research Centre, S.T.Hindu College, Nagercoil, Tamilnadu, India.
}

\begin{abstract}
Pure and $\mathrm{KBr}$ doped crystals of $\mathrm{ADP}$ were grown by slow evaporation technique from the supersaturated solution of ADP at room temperature. The tetragonal structure of the grown crystals was observed by powder X-ray diffraction analysis. FTIR spectra revealed the presence of functional groups present in the grown crystals. The UV-Vis spectral analysis shows high transparency in the entire visible region. The band gap value of the pure ADP crystal was found assuming indirect transition.
\end{abstract}

Key Words: ADP, Powder XRD, FTIR, Band gap

\section{INTRODUCTION}

Ammonium dihydrogen phosphate, $\mathrm{NH}_{4} \mathrm{H}_{2} \mathrm{PO}_{4}$ (abbreviated as ADP) is a well-known antiferroelectric crystal. A study on ADP crystals is very interesting in view of their dielectric, anti ferroelectric and optical properties. Most important applications of ADP crystals are that they are used as electro-optical modulator, harmonic generators, and parametric generator and as monochromators for X-ray fluorescence analysis [1]. ADP was belongs to scalenohedral (twelve faced) class of tetragonal crystal system [2, 3]. It is well known that, the crystal habit of ammonium dihydrogen phosphate can be modified by certain ions when they are incorporated into crystal lattice. In this study pure ADP and $\mathrm{KBr}$ doped ADP crystals were grown by solution growth using slow evaporation technique at room temperature. The grown crystals were subjected to Powder X-ray diffraction, FTIR and UV-Visible spectral studies. The characterization results are reported here.

\section{EXPERIMENTAL}

\subsection{Crystal Growth}

Single crystals of pure ADP and $\mathrm{KBr}$ doped ADP were grown from supersaturated solution of AR grade salt of ADP and Potassium bromide, respectively. The pure and doped crystals were grown separately by the supersaturated solution. For doped ADP crystal, $0.01 \mathrm{~mol} \%$ of $\mathrm{KBr}$ was added to the super saturated solution of ADP. Both the solutions were stirred well up to get homogeneous solution using magnetic stirrer. The homogeneous solutions were filtered using filter paper. The filtered solutions were allowed to slow evaporation, placing in a dust free zone. Colourless crystals were grown within 15-30 days. Transparent good quality crystals were used for characterizations.

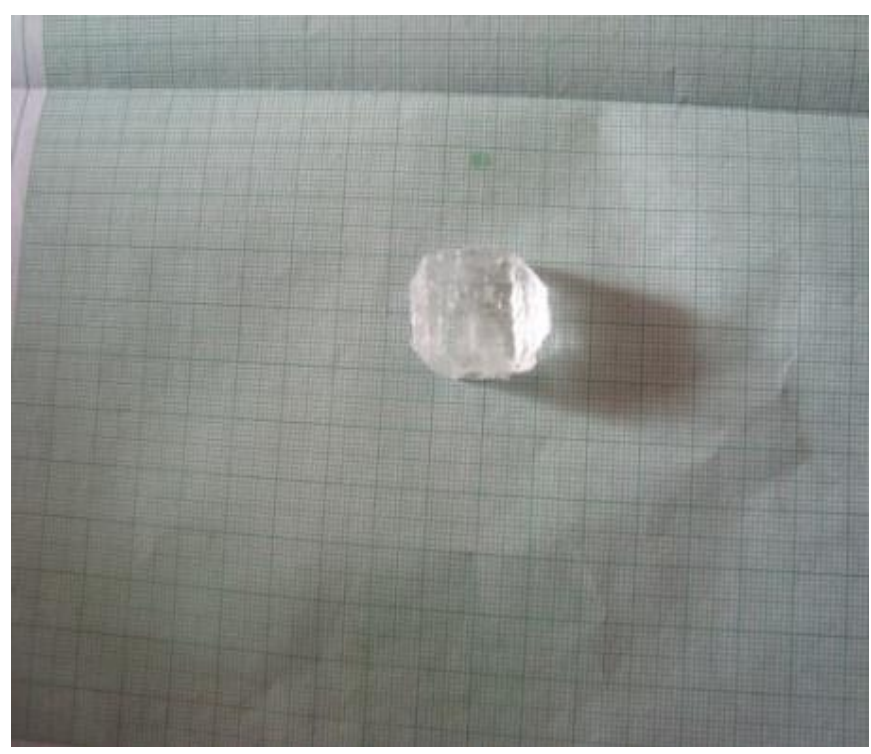

Fig -1: Photograph of pure ADP crystal

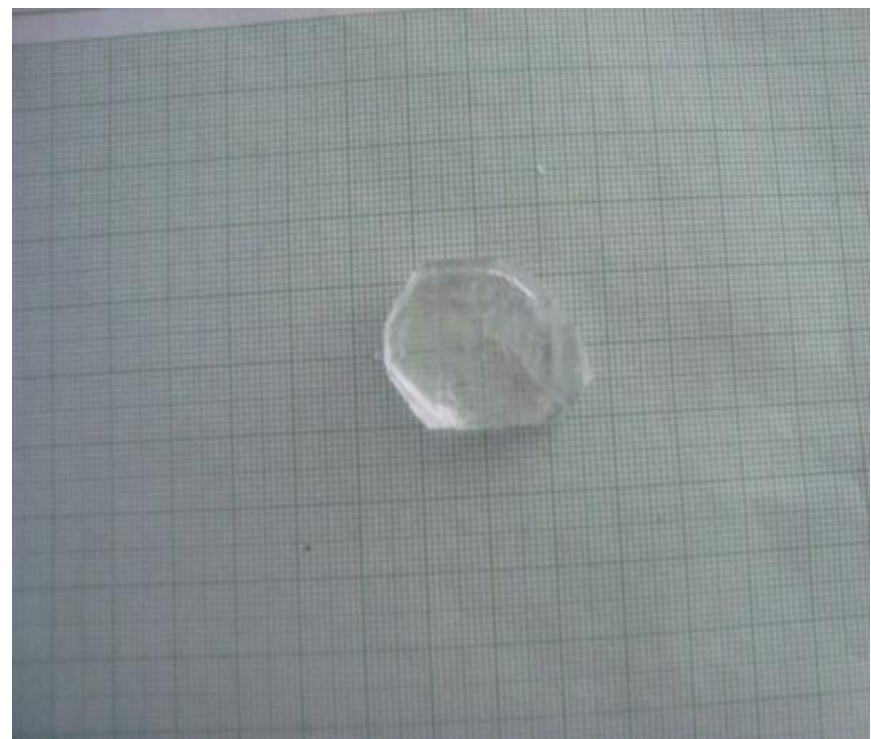

Fig -2: Photograph of KBr doped ADP crystal 


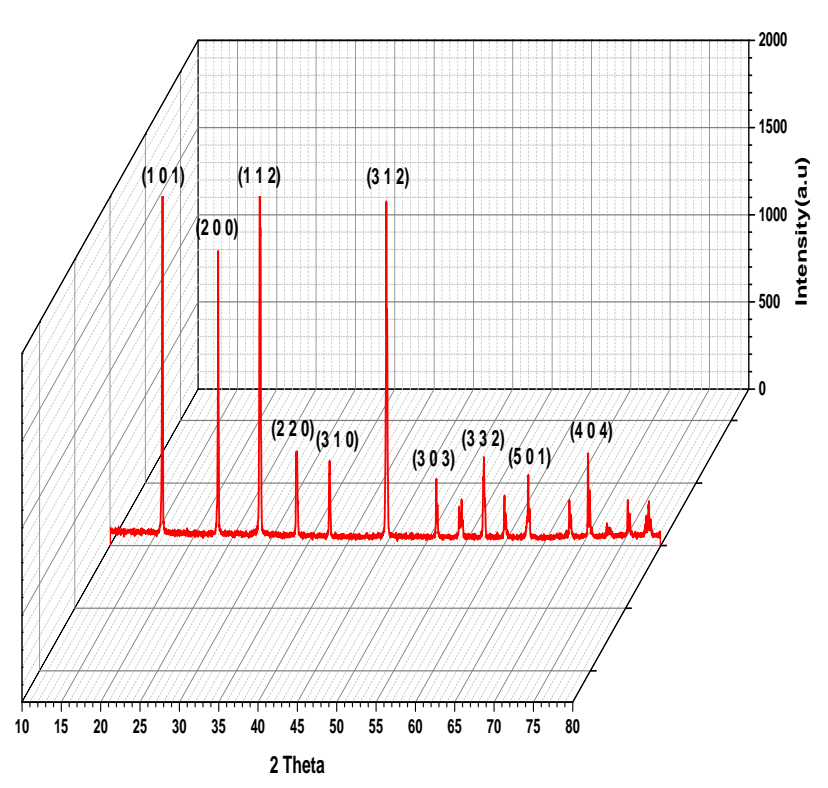

Fig -3: Powder X-ray diffraction pattern for pure ADP crystal

\subsection{Material Characterization}

The pure and $\mathrm{KBr}$ doped ADP single crystals were characterized by Powder X-ray diffraction using XPERTPRO diffractometer. FTIR spectra of the grown crystals were characterized by Jasco 4100 Spectrophotometer equipped with ATR. UV-Vis absorption spectra of the grown crystals were recorded using Systronics UV-Vis double beam spectrophotometer.

\section{RESULTS AND DISCUSSION}

\subsection{Powder X-ray diffraction analysis}

The structure of the pure and $\mathrm{KBr}$ doped ADP crystals were identified from powder X-ray diffraction using $\mathrm{CuK} \alpha$ radiation of wavelength $1.54060 \AA$. The data were recorded in the $2 \theta$ range from $10-80^{\circ}$.

Figure (3) and (4) show the powder XRD patterns of pure and $\mathrm{KBr}$ doped ADP crystals. The obtained data were in good agreement with standard JCPDS (JCPDS: 37-1479) of ADP crystal with tetragonal crystal system. The reflection planes were indexed in accordance with the JCPDS. The lattice parameter values of ' $\mathrm{a}$ ' and ' $c$ ' for pure and $\mathrm{KBr}$ doped ADP crystals were found to be $a=7.50424 \AA$, $\mathrm{c}=7.54530 \AA$ and $\mathrm{a}=7.49005 \AA, \mathrm{c}=7.54646 \AA$, respectively. The calculated volume for pure ADP is $424.904(\AA)^{3}$ and $423.363(\AA)^{3}$ for $\mathrm{KBr}$ doped ADP crystal. The intensity of the $\mathrm{KBr}$ doped $\mathrm{ADP}$ crystal increased when compared to pure ADP. The change in intensity, volume, lattice parameters ' $a$ ' and ' $b$ ' suggest that the structure of $\mathrm{KBr}$ doped crystal was slightly distorted when compared to pure ADP crystal. It is seen from the PXRD spectrum of pure and $\mathrm{KBr}$ doped ADP crystals that there is no additional peak, but only change in the intensity of the peaks. This confirms there is no additional phase produces due to influence of doping [4].

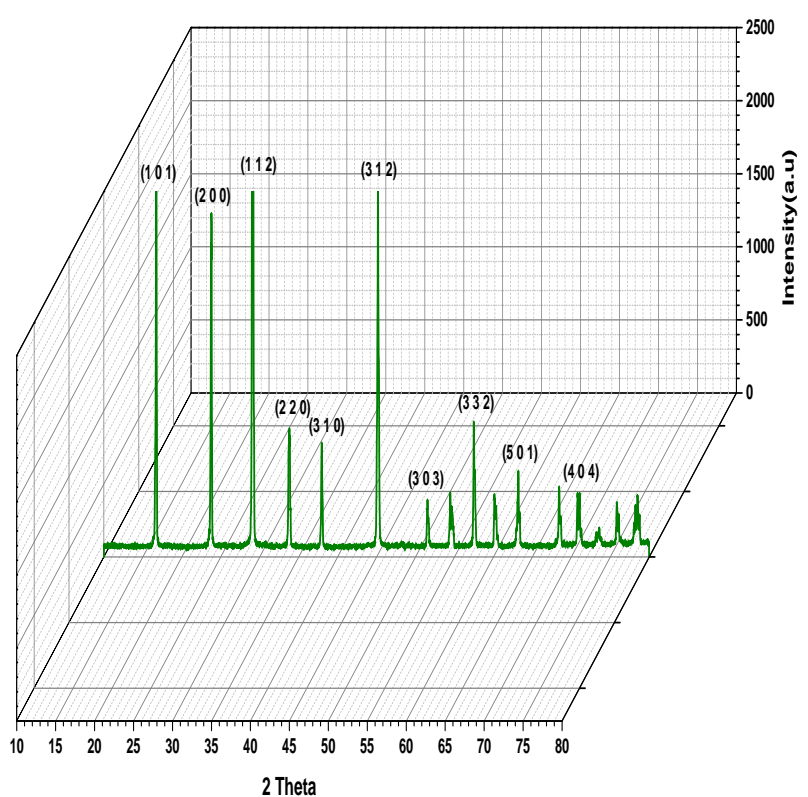

Fig -4: Powder X-ray diffraction pattern for $\mathrm{KBr}$ doped ADP crystal

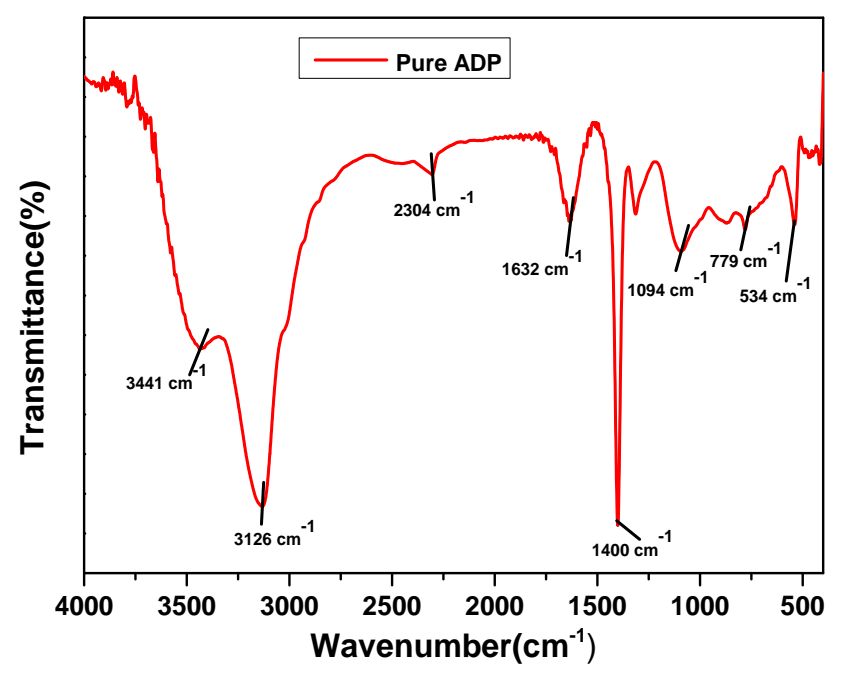

Fig -5: FTIR spectrum of pure ADP crystal

\section{FTIR Analysis}

The functional groups present in the pure and $\mathrm{KBr}$ doped ADP crystals were analyzed by FTIR spectroscopy. Figure (5) shows the FTIR spectrum of pure ADP crystal. For pure ADP crystal, the band at 3441 and $3126 \mathrm{~cm}^{-1}$ was assigned to stretching vibrational mode of $\mathrm{O}-\mathrm{H}$ group [5]. Additionally the N-H vibrations were also assigned to 3441 $\mathrm{cm}^{-1}[4]$. The band at $1632 \mathrm{~cm}^{-1}$ was assigned to bending vibrational mode of $\mathrm{O}-\mathrm{H}$ group. The vibrational mode of $\mathrm{P}-$ $\mathrm{O}-\mathrm{H}$ group was observed at $1094 \mathrm{~cm}^{-1}$. The stretching vibrational mode of $\mathrm{PO}_{4}$ group was observed at $534 \mathrm{~cm}^{-1}[6]$. The vibration at $1400 \mathrm{~cm}^{-1}$ was assigned to stretching vibrational mode of $\mathrm{NH}_{4}$. 


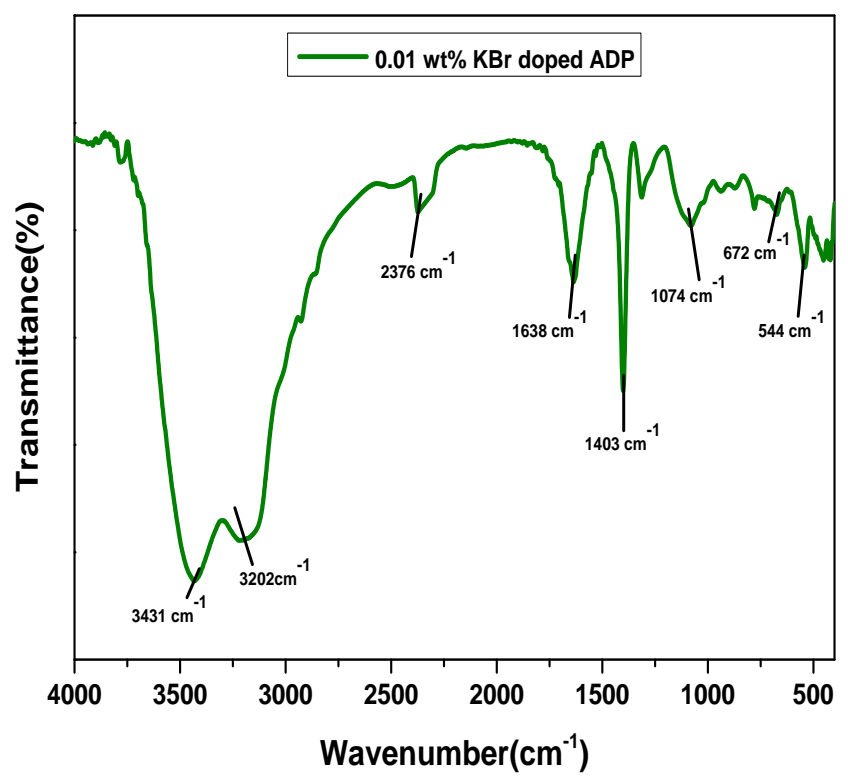

Fig -6: FTIR spectrum of KBr doped ADP crystal

Figure (6) shows the FTIR spectrum of $\mathrm{KBr}$ doped ADP crystal. Very slight shifts in vibrational bands were observed for $\mathrm{KBr}$ doped ADP crystal due to inclusion of doping. The vibrational band at $3431 \mathrm{~cm}^{-1}$ was also assigned to vibration of $\mathrm{N}-\mathrm{H}$ band. The band at $1638 \mathrm{~cm}^{-1}$ was assigned to bending vibrational mode of $\mathrm{O}-\mathrm{H}$ group. The vibrational mode of P-O-H group was observed at $1074 \mathrm{~cm}^{-1}$. The stretching vibrational mode of $\mathrm{PO}_{4}$ group was observed at $544 \mathrm{~cm}^{-1}$. The shifting band of $\mathrm{NH}_{4}$ was observed at 1400 $\mathrm{cm}^{-1}$. All these vibrational bands were well matched with the previous report [7]. The vibrations of $\mathrm{KBr}$ were not clearly resolved from the FTIR spectrum of the pure ADP, it might happen in a trace amount below the deductibility limit.

\subsection{UV-Vis Spectral analysis}

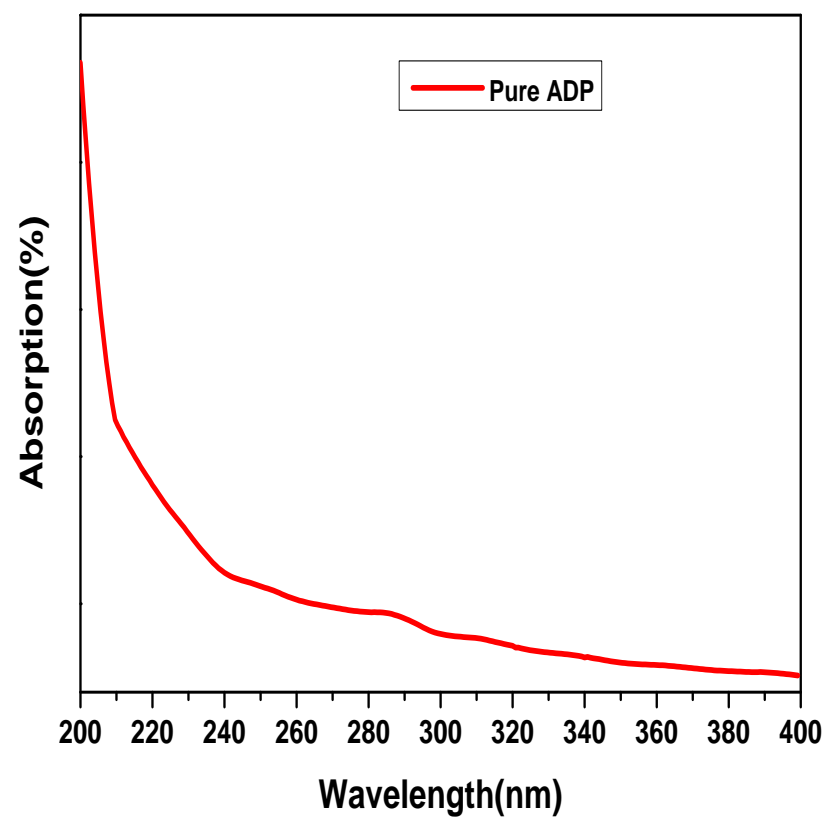

Fig -7: UV-Vis absorption spectrum of pure ADP crystal

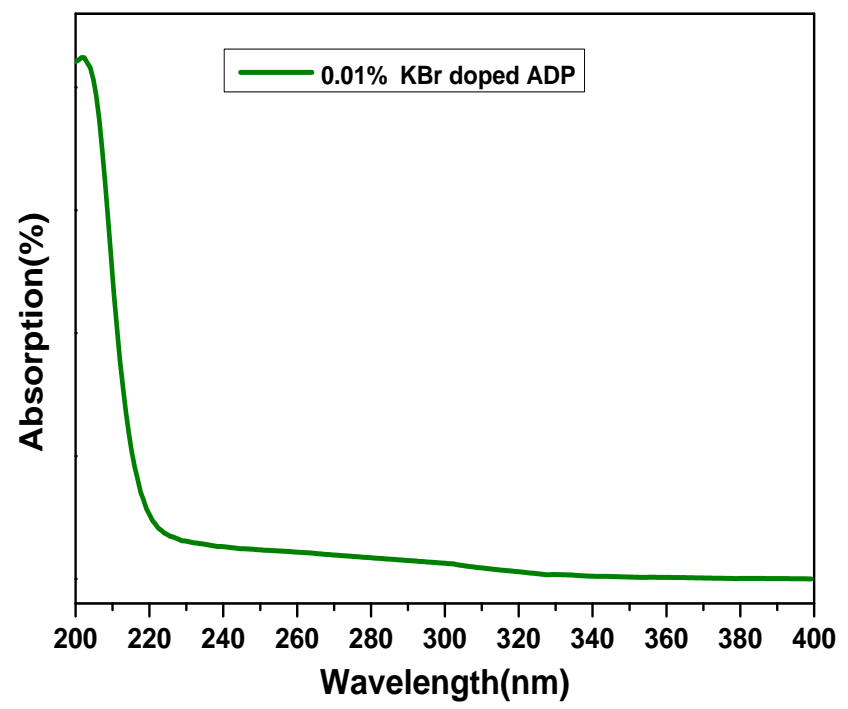

Fig -8: UV-Vis absorption spectrum of $\mathrm{KBr}$ doped ADP crystal

UV-Vis absorption spectrum of pure and $\mathrm{KBr}$ doped ADP crystals were recorded in the range of $200-600 \mathrm{~cm}^{-1}$. Figure (7) and (8) show the UV-Visible absorption spectrum of pure and $\mathrm{KBr}$ doped ADP crystal. The spectrum of pure and $\mathrm{KBr}$ doped ADP crystals shows the full transmission in the entire visible region. So the pure and $\mathrm{KBr}$ doped ADP crystal is a very good material for electro - optic and NLO applications [8].

The optical band gap value of pure and $\mathrm{KBr}$ doped ADP crystals were calculated using the Tauc's relation, $(\alpha h v)^{\mathrm{n}}=\mathrm{A}\left(\mathrm{h} v-\mathrm{E}_{\mathrm{g}}\right)$

Where ' $\alpha$ ' is the absorption coefficient, ' $\mathrm{A}$ ' is a constant, ' $\mathrm{Eg}$ ' is the band gap energy, ' $v$ ' is the frequency of incident beam, ' $h$ ' is the Planck's constant, ' $n$ ' is the index value depends on nature of the transition. For direct allowed transitions $n=2$ and for indirect allowed transition $n=1 / 2$. Assuming the indirect band gap, the plot is drawn $(\alpha h v)^{1 / 2}$ against $h v$. The intercept of the straight line on the $h v$ axis gives the indirect band gap value [9].

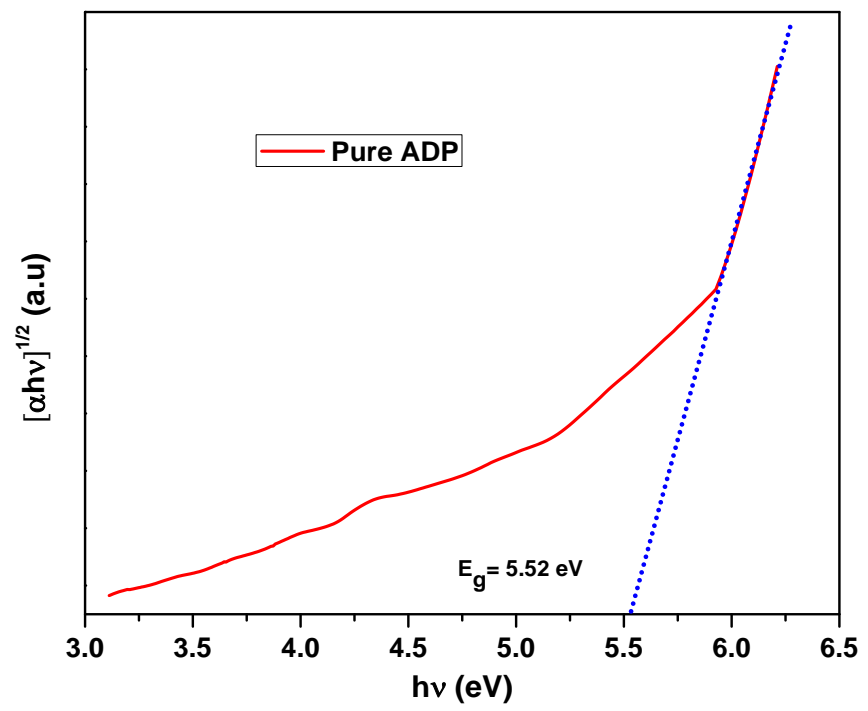

Fig -9: Tauc plot of ADP crystal 


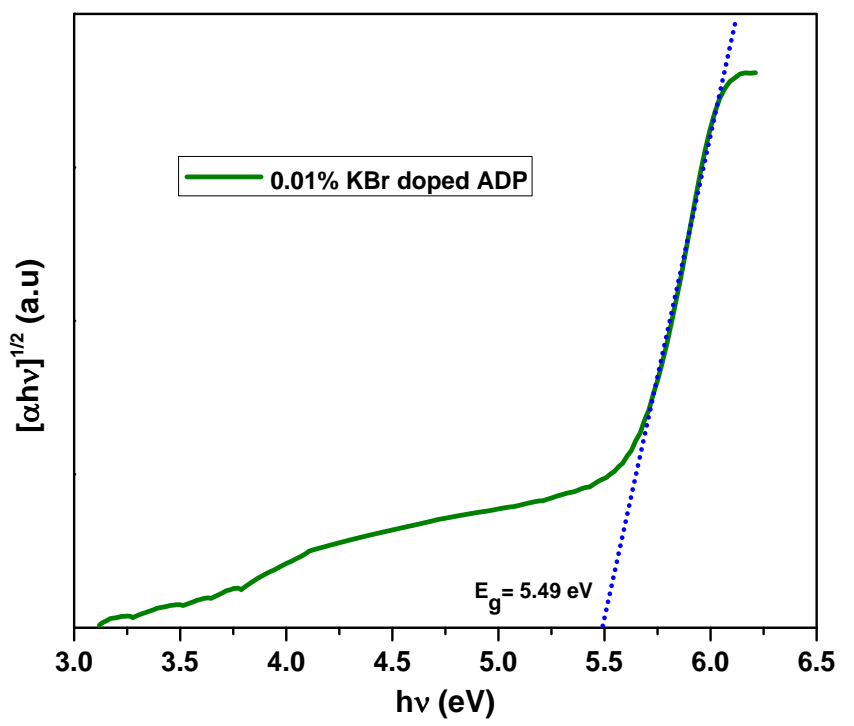

Fig -10: Tauc plot of $\mathrm{KBr}$ doped ADP crystal

Figure (9) and (10) show the Tauc's plot for pure and $\mathrm{KBr}$ doped ADP crystals respectively. The indirect band gap value of pure and $\mathrm{KBr}$ doped crystals found from the Tauc plot is 5.52 and $5.49 \mathrm{eV}$, respectively. This band gap value is close to the reported value of $4.7 \mathrm{eV}$ [10].

\section{CONCLUSIONS}

Pure and $\mathrm{KBr}$ doped ADP crystals were grown using low temperature solution growth technique by slow evaporation method. X-Ray powder diffraction revealed the distortion in the crystal lattice due to the inclusion of doping material $\mathrm{KBr}$. FTIR spectra confirms the vibrational modes of ADP crystal. UV-Vis spectral analysis shows the band gap value of $5.52 \mathrm{eV}$ for pure ADP crystals.

\section{ACKNOWLEDGEMENT}

The authors gratefully acknowledge the Management of S.T.Hindu College, Nagercoil.

\section{REFERENCES}

[1]. P. Shenoy, K. V. Bangera, G. K. Shivakumar, Growth and thermal studies on pure ADP, KDP and mixed K1$\mathrm{x}(\mathrm{NH} 4) \mathrm{xH}_{2} \mathrm{PO}_{4}$ crystals, Cryst. Res. Technol. 45 (2010) $825-829$.

[2]. M. Meena and C. K. Mahadevan, Growth and electrical characterization of L-arginine added KDP and ADP single crystals, Cryst. Res. Technol. 43 (2008) $166-172$.

[3]. K. Sethuraman, R. Ramesh Babu, R. Gopalakrishnan, P. Ramasamy, Unidirectional growth of $\langle 110\rangle$ ammonium dihydrogen orthophosphate single crystal by Sankaranarayanan-Ramasamy method, Journal of Crystal Growth, 294 (2006) 349-352.

[4]. P.V. Dhanaraj , G. Bhagavannarayana, N.P. Rajesh, Effect of amino acid additives on crystal growth parameters and properties of ammonium dihydrogen orthophosphate crystals, Materials Chemistry and Physics, 112 (2008) 490-495.

[5]. Briyan C. Smith, Infrared Spectral Interpretation-A systematic Approach, CRC Press (1999), New York.

[6]. J. Anitha Hudson, C.K. Mahadevan, C.M. Padma, Growth and Characterization of ADP Single Crystals Added With CdS, International Journal of Engineering Research and Applications, 4 (2014) 257-266.

[7]. P.V.Dhanaraj, N.P.Rajesh, Crystallisation and material Science of Modern artificial and natural crystals (Edited by Dr.Elena Borisenko, (2012) 79.

[8]. P. Rajesh, P. Ramasamy, Binay Kumar, G. Bhagavannarayana, Effect of cobalt and DL-malic acid on the growth rate, crystalline perfection, optical, mechanical, dielectric, piezoelectric properties and SHG efficiency of ADP single crystals, Physica B, 405 (2010) 2401-2406.

[9]. Sunil Chaki, M. P. Deshpande, Jiten P. Tailor, Mahesh D. Chaudhary, Kanchan Mahato, Growth and Characterization of ADP Single Crystal, American Journal of Condensed Matter Physics, 2 (2012) 22-26.

[10]. R.N. Shaikh, M. Anis, M.D. Shirsat, S.S. Hussaini, Investigation on the Linear and Nonlinear Optical Properties of L-Lysine Doped Ammonium Dihydrogen Phosphate Crystal for NLO Applications, IOSRJournal of Applied Physics, 6 (2014) 42-46.

\section{BIOGRAPHIES}

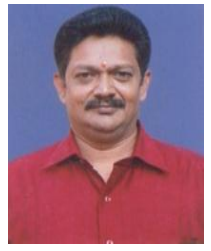

N.SIVA, M.Sc., MCA., M.Tech., Principal, KNSK Polytechnic College, Nagercoil.

Email: mnsivaram@yahoo.com

Mobile: 9486915666

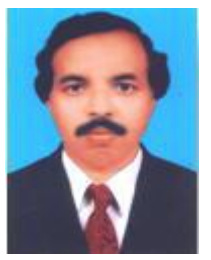

Dr.S.PERUMAL, M.Sc., M.Phil., Ph.D., Principal, S.T.Hindu College, Nagercoil629002.

Email: spee58@gmail.com

Mobile: 9443119441

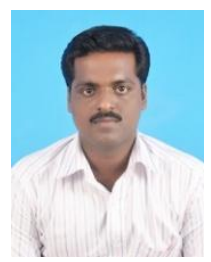

Mr. K.MONIKANDA PRABU, M.Sc., M.Phil., Research Scholar, Physics Research Centre, S.T.Hindu College, Nagercoil-629002.

Email: mkprabu1985@gmail.com Mobile: 9095964636 